\title{
High-Speed Photography
}

\author{
Dennis L. Paisley \\ Los Alamos National Laboratory \\ Los Alamos, New Mexico
}

\author{
Mikhail Ya. Schelev \\ General Physics Institute \\ Moscow, Russia
}

High-speed photography, like traditional photography, can provide quantitative information as well as qualitative. Nothing enlightens and opens the human mind like an image whether for technical information or esthetics. A professor-friend of mine (DLP) once stated, "I hate it when a colleague says a particular function is time independent. Almost every function or natural phenomena is time dependent if you observe the right time scale!' In 1851, William Henry Fox Talbot attached a page of the London Times to a wheel, which he then rotated in front of his wet plate camera in a darkened room. As the wheel rotated, Talbot exposed a few square inches of the newspaper page for about 1/2000th of a second, using spark illumination from Leyden jars. This experiment resulted in a readable image and ushered in a new science and technology: high-speed photography (HSP). In the 1870s Eadweard Muybridge used HSP to answer the question, "Are all four hooves of a horse off the ground at any one time?' In the early 1900 s telephone circuit switch closures and "bounce", were studied by HSP. HSP has come a long way from these early days.

Today HSP includes videography, gated-CCDs, and a plethora of combined technologies for specialized applications. HSP is used to study such diverse subjects as micrometeorite impact on satellites, laser welding, inertial confinement fusion (ICF), laser surgical procedures, laser pulse duration, communications, automotive airbags, lightning, and defense technologies. The late Dr. Harold E. Edgerton's stroboscopic images of athletes in action and birds in flight did much to inform the public of the benefits of HSP. Many scientific HSP images are not so enlightening to the uninformed but to those who know and collect the information it might as well be a view of any of the "Wonders of the World.' The late Dr. J. S. Courtney-Pratt patented the first electronic streak and imaging tube to convert photons to electrons and back by the use of electronics, giving rise to the term photonics that is now broadly used and applied. Most HSP research and new hardware has been developed as international efforts by major research laboratories in Russia, France, the UK, Germany, Japan, Canada, China, and the USA with significant contributions by individuals in many other countries.

Unfortunately, most scientific and engineering applications of HSP are learned "on the job" rather than in a formal classroom or university research laboratory. Most universities do not teach HSP courses in a formal manner and as such most students are unaware of its potential. Hopefully this special section will encourage young students to become aware and interested in how HSP can be a tool to solve technical problems. The papers in this special section represent some of the technologies and applications of HSP. For a more complete understanding of the technology and its diversity one should refer to the Proceedings of the International Congress on High Speed Photography and Photonics (ICHSPP) that has met biennially since 1952 . Some of these papers will be orally presented at the 23rd ICHSPP in Moscow, September 2025, 1998. Information regarding the 23rd ICHSPP can be found on the SPIE web page: www.spie.org. The editors encourage your attendance and participation.

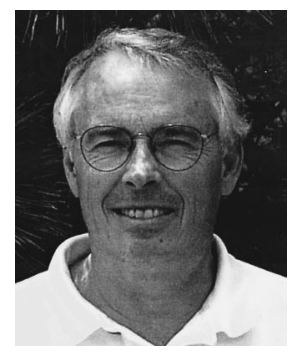

Dennis L. Paisley is a staff member and physicist at Los Alamos National Laboratory, New Mexico. He received his BS in physics from Western Illinois University and an MS in physics from Xavier University, Cincinnati, Ohio. Previously he was a staff member at the Univ. of Dayton Impact Physics Institute and Mound Laboratory in Ohio. Mr. Paisley is a Fellow of SPIE and U.S. National Delegate to the International Congresses on High Speed Photography and Photonics. He edited the SPIE Milestone Series M109 on high-speed photography, and has chaired U.S. and International conferences. He has numerous publications on applications of high-speed photography, photonics, interferometry and pulsed lasers for experimental diagnostics, explosives, plasmas, and laser-matter interaction and ablation. He has four patents on laser-matter interaction.



Mikhail Ya. Schelev graduated from the Instrumentation Faculty of Baumann Moscow High Technological School (Technological University) in 1962. He received his $\mathrm{PhD}$ in engineering in 1969 and doctor of science degree in physics and mathematics in 1981 both from Lebedev Physical Institute, and the title of professor in physical electronics from General Physics Institute, Russian Academy of Sciences in 1985. He was awarded the Shardin International Gold Medal from the German Physical Society (1972) and International Photonics Award from SPIE (1988). He also received Lenin's Komsomol Award (1971) and the USSR State Award (1986). Currently he is head of the Photoelectronics Department, General Physics Institute, Russian Academy of Sciences. His research interests are in the areas of laser physics, femtosecond technology, high-speed image converter photography, and related applications. 